\title{
EFFECT OF SHORT-TERM MINDFULNESS INDUCTION ON MYSIDE BIAS AND MISERLY PROCESSING: A PRELIMINARY STUDY
}

\author{
Marek JURKOVIČ \\ Institute of Experimental Psychology \\ Center of Social and Psychological Sciences, Slovak Academy of Sciences \\ Dúbravská cesta 9, 84104 Bratislava, Slovak Republic \\ E-mail: marek.jurkovic@savba.sk
}

\begin{abstract}
The goal of the current study was to explore the possible effect of a short mindfulness meditation on decreasing a tendency for miserly processing and degree of myside bias. My sample consisted of 76 students that were assigned into three groups: one with short mindfulness intervention and two control groups (one was given a lecture on cognitive biases and second group was given mind-wandering instruction). The groups did not significantly differ in any of the measured variables (with one minor exception). The results indicate that short-term mindfulness induction was unsuccessful in changing the proclivity for cognitive biases, contrary to what the author predicted.
\end{abstract}

Key words: mindfulness, miserly processing, myside bias

The ability to reflect on one's own information processing appears to be crucial for rationality (Stanovich, 2011). This notion is based on a hypothesis, that only an individual with a certain degree of knowledge of his own cognition might be capable of adequately regulating his reasoning and inhibit various cognitive biases. I propose an approach to gaining knowledge about one's own cognitive processes that is based on mindfulness meditation. Mindfulness can be defined as "paying attention in a particular way: on purpose, in the present moment, and nonjudgmentally" (Kabat-Zinn, 1994). Developed metacognitive skills are a necessity

Acknowledgements

This work was supported by the Slovak grant agency VEGA 2/0064/13: Decision Making of Experts: Using Intuition for Solution of Strategic Tasks. for a well-performing 'reflective mind' and thus for rational thought. Not only is practice of mindfulness meditation dependent on the development of relevant metacognitive skills and knowledge (Jankowski \& Holas, 2014), it also provides means for a better selfknowledge as the mindful awareness draws attention to details of individual's mental life. During a mindfulness meditation, the practitioner also trains his executive functions as he gradually learns how to inhibit mind-wandering and habitual reactions and trains cognitive shifting while trying to focus on changing mental contents (Moore \& Malinowski, 2009).

These aspects of mindfulness seem to be contrary to preference for lesser cognitive load and thus heuristic processing. While being mindful, one should diligently take notice of passing mental phenomena and regard even seemingly trite experiences with 
curiosity. This appears to go against the tendency for fast and superficial heuristic processing (miserly processing). Secondly, mindful non-judgmental and decentered perspective (Jankowski \& Holas, 2014) might give an individual certain distance from his own beliefs or convictions, which might prove helpful for reducing confirmation/ myside bias. Myside bias in context of this study means the tendency to evaluate information based on beliefs or opinions held by an individual or based on belonging to specific group/status.

Therefore, the main rationale for this study was the fact, that possible effects of mindfulness on cognitive biases and human rationality have not been studied so far, with only few exceptions (Emanuel, Updegraff, Kalmbach, \& Ciesla, 2010; Hafenbrack, Kinias, \& Barsade, 2013) of which one examined merely a relationship with trait mindfulness and found that only one particular facet of mindfulness was related to a degree of biased affective forecasting (Emanuel et al., 2010). Another study (Noone, Bunting, \& Hogan, 2016) measuring trait mindfulness found that higher levels of mindfulness are related to critical thinking and executive functions. Yet other studies (Heeren, Van Broeck, \& Philippot, 2009; Mrazek, Franklin, Phillips, Baird, \& Schooler, 2013; Teper \& Inzlicht, 2013) found that mindfulness affects executive functions and these are in turn possibly related to inhibition of cognitive biases, because training of inhibition in mindfulness meditations might help in inhibiting fast heuristic reactions like those measured by the Cognitive Reflection Test (Frederick, 2005).

I attempted to examine possible effects of short-term mindfulness induction on the amount of myside bias and tendency for miserly processing. Although the majority of studies have focused on the effects of longterm training of mindfulness, some studies (Arch \& Craske, 2006; Hafenbrack et al., 2013; Kiken \& Shook, 2011) have found that even short-term mindfulness induction (all studies used 15 minute recorded inductions) might have an effect on various domains. The most relevant finding is related to a reduction in sunk-cost bias (Hafenbrack et al., 2013). The goal of the current study was to find out if short-term mindfulness is suitable as a method to reduce other cognitive biases and thus improve decision-making. Unlike long-term mindfulness training programs (usually lasting for an eight week period), a short-term mindfulness induction, if demonstrated to be effective, might be more practical and thus could be more easily deployed in various commonplace contexts (e.g., workplace). The goal of this study was to gather evidence that mindfulness meditation might have a larger effect than explicit education on cognitive biases, therefore, the control groups consisted of one mind-wandering condition (natural non-mindful state) and one condition with a lecture on cognitive biases.

\section{Method}

\section{Participants}

The participants were 76 undergraduate students (51 females) of various pedagogic disciplines recruited through psychology courses (but participants were not students of psychological discipline and psychology was only a minor part in their courses) and were given credits for their participation. Mean age was $20.9(S D=2.13)$. Convenience sampling was the employed method for participant selection. 


\section{Procedure}

Participants were randomly assigned to three conditions: mindfulness meditation $(n=25)$; lecture on cognitive biases $(n=30)$ and mind-wandering group $(n=21)$.

Participants in the mindfulness meditation condition listened to a recording of a guided meditation translated from a 'Breathscape and Bodyscape' recording (KabatZinn, 2005). Participants in the mind-wandering condition listened to a recording that instructed them to think of whatever they want and was based on previously used paradigm (Hafenbrack et al., 2013). Participants in the last control group were given a lecture by the author of the study on various cognitive biases and on certain basic principles of critical thinking. All interventions lasted 15 minutes and were performed simultaneously in separate rooms. All materials measuring dependent variables were administered post-intervention (after mindfulness induction) and participants answered them in the same room. Post-test only measurement was chosen due to time and logistic constraints and due to a high possibility of transfer effect.

\section{Materials}

Participants answered questions about their demographics and filled out a 39-item Five-Facet Mindfulness Questionnaire FFMQ (Baer, Smith, Hopkins, Krietemeyer, $\&$ Toney, 2006) to measure effectiveness of mindfulness induction with items like "I am easily distracted". This questionnaire consists of five subscales measuring different aspects of mindfulness experience (Observing, Describing, Acting with Awareness,
Non-judgmental Attitude and Non-reactivity). Participants were subsequently solving the 7-item CRT-7 (Toplak, West, \& Stanovich, 2014), which is an expanded version of the Cognitive Reflection Task (Frederick, 2005) that measures the tendency to override miserly processing. CRT-7 consists of items like: "Jerry received both the $15^{\text {th }}$ highest and the $15^{\text {th }}$ lowest mark in the class. How many students are in the class?"

As a measure of myside bias, participants were asked to indicate their agreement or disagreement with 14 statements on controversial themes that were likely to induce myside bias (negative effects of smoking, drinking, marijuana consumption, differences between believers and non-believers, abortions, registered partnership of homosexuals and national politics). Some of the statements were adopted from a paradigm used in previous studies (e.g., Stanovich \& West, 2007), some of the statements related to current national controversies were introduced in this study (e.g., "President Kiska bought a presidential chair with money from usury." which was a claim promoted by his opponents during a recent presidential campaign). Participants indicated their agreement on a 6-point scale ( 1 = Strongly agree, $6=$ Strongly disagree). Participants subsequently indicated their prior demographic statuses relevant to subjects such as: weekly frequency of alcohol and cigarettes consumption, their opinion on legality of abortions, belief in god, their preferred political movements and their opinion on legalization of marijuana.

\section{Results}

Firstly, I examined whether different conditions translated into different scores on FFMQ (Cronbach's alpha was 0.808 for 
Awareness subscale, 0.822 for Non-judging subscale and 0.742 for Non-reactivity scale, 0.94 for cumulative FFMQ score, other subscales did not attain acceptable levels of Cronbach's alpha). A Kruskal-Wallis H test showed that there were no significant differences between conditions on either subscales or a cumulative FFMQ score ( $\mathrm{p}$ was 0.245 for observing subscale, 0.922 for nonjudging subscale, 0.556 for non-reactivity subscale).

I examined the difference between conditions on the CRT-7 score (Cronbach's alpha wasacceptable 0.681).AKruskal-Wallis Htest showed that there was no statistically signifi- cant difference in CRT-7 score between the different conditions, $\chi^{2}(2)=0.597, p=0.742$.

Subsequently, I examined if the answers to statements displayed signs of myside bias and if conditions differed in the level of myside bias. Table 1 shows which statements displayed myside bias in relation to a prior demographic status ( 9 out of 14) and mean ranks as an indicator of how statements were treated differently by participants with different demographic status (effects were in the expected direction).

Statements with no myside bias were excluded from further analysis by two-way ANOVA. There were no statistically signifi-

Table 1 Myside bias as a function of prior demographic status

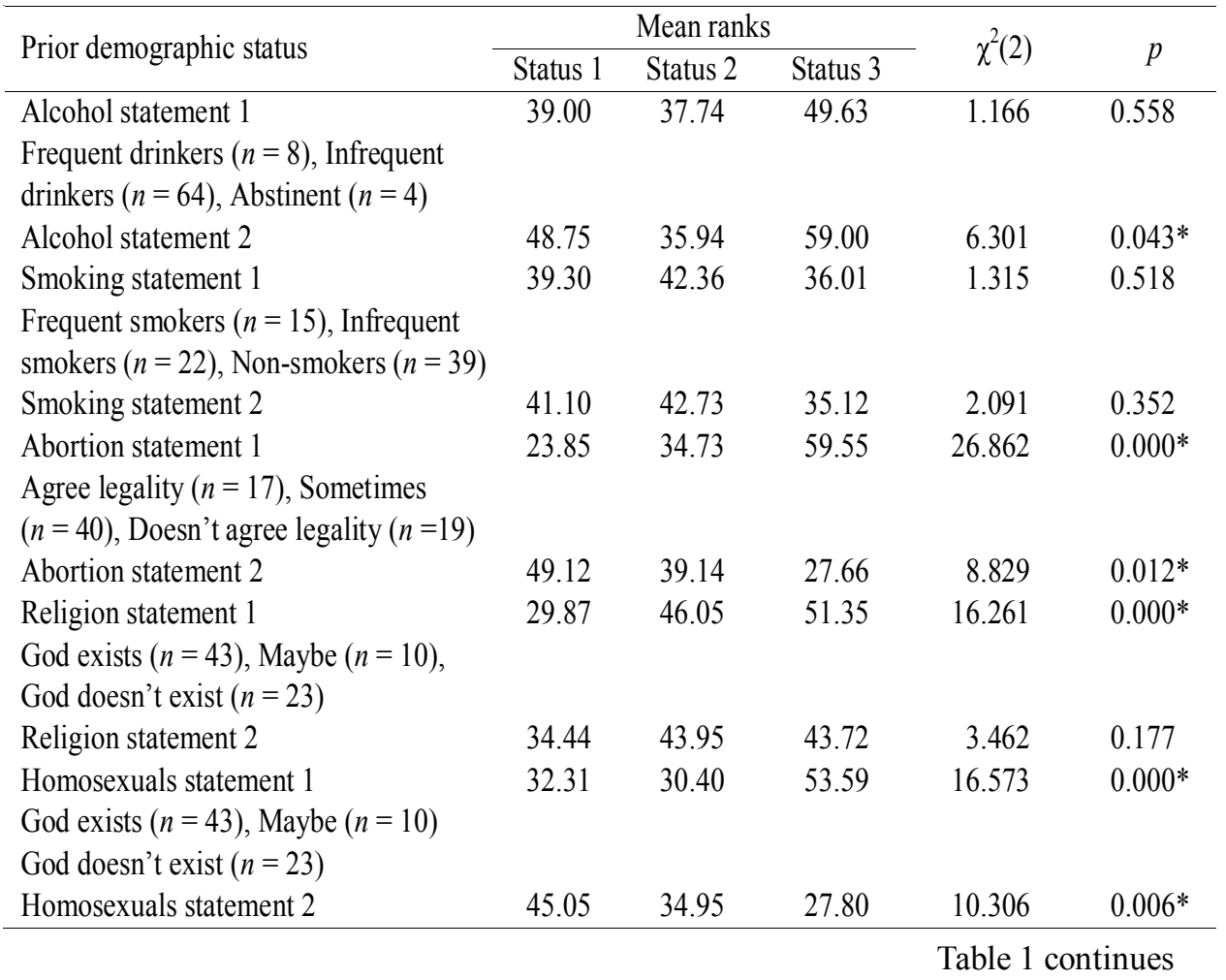


Table 1 continued

\begin{tabular}{|c|c|c|c|c|c|c|c|c|}
\hline \multirow{2}{*}{\multicolumn{3}{|c|}{ Prior demographic status }} & \multicolumn{2}{|c|}{ Mean ranks } & & \multirow{2}{*}{\multicolumn{2}{|c|}{$\chi^{2}(1)$}} & \multirow[b]{2}{*}{$p$} \\
\hline & & & \multicolumn{2}{|c|}{ Status $1 \quad$ Status 2} & & & & \\
\hline \multicolumn{3}{|l|}{ Marijuana statement 1} & 47.69 & 33.44 & & \multicolumn{2}{|c|}{7.202} & $0.007^{*}$ \\
\hline \multicolumn{9}{|c|}{ Pro legalization $(n=24)$} \\
\hline \multicolumn{9}{|c|}{ Against legalization $(n=51)$} \\
\hline \multicolumn{3}{|c|}{ Marijuana statement 2} & 29.17 & 42.16 & & \multicolumn{2}{|c|}{6.2019} & $0.013^{*}$ \\
\hline \multirow{2}{*}{$\begin{array}{l}\text { Prior demographic } \\
\text { status }\end{array}$} & \multicolumn{6}{|c|}{ Mean ranks } & \multirow{2}{*}{$\chi^{2}(5)$} & \multirow[b]{2}{*}{$p$} \\
\hline & Status 1 & Status 2 & Status 3 & Status 4 & Status 5 & Status 6 & & \\
\hline Politics statement 1 & 36.83 & 21.83 & 21.83 & 49.90 & 41.58 & 45.17 & 15.776 & $0.008^{*}$ \\
\hline \multirow{4}{*}{\multicolumn{9}{|c|}{$\begin{array}{l}\text { Conservative right } \\
(n=6), \text { Liberal right } \\
(n=12), \text { Liberal left } \\
(n=6)\end{array}$}} \\
\hline & & & & & & & & \\
\hline & & & & & & & & \\
\hline & & & & & & & & \\
\hline \multirow{3}{*}{\multicolumn{9}{|c|}{$\begin{array}{l}\text { Conservative left } \\
(n=10), \text { Not voting } \\
(n=32), \text { Other }(n=9)\end{array}$}} \\
\hline & & & & & & & & \\
\hline & & & & & & & & \\
\hline Politics statement 2 & 43.08 & 49.00 & 48.67 & 32.95 & 31.27 & 42.39 & 9.215 & 0.101 \\
\hline
\end{tabular}

*statistically significant differences at level $p<0.05$

Table 2 ANOVA (Prior Demographic Status $x$ Condition)

\begin{tabular}{lcccc}
\hline Statements & df & F & $p$ & $\begin{array}{c}\text { Effect size - } \\
\text { partial } \eta^{2}\end{array}$ \\
\hline Alcohol statement 2 & $(3.68)$ & 0.992 & 0.402 & 0.042 \\
Abortion statement 1 & $(4.67)$ & 0.825 & 0.514 & 0.047 \\
Abortion statement 2 & $(4.67)$ & 0.473 & 0.755 & 0.027 \\
Religion statement 1 & $(4.67)$ & 0.469 & 0.758 & 0.027 \\
Homosexuals statement 1 & $(4.67)$ & 0.681 & 0.608 & 0.039 \\
Homosexuals statement 2 & $(4.67)$ & 1.349 & 0.261 & 0.075 \\
Marijuana statement 1 & $(2.69)$ & 0.697 & 0.385 & 0.027 \\
Marijuana statement 2 & $(2.69)$ & 5.146 & $0.008^{*}$ & 0.130 \\
Politics statement 1 & $(10.57)$ & 0.468 & 0.904 & 0.076 \\
\hline
\end{tabular}

*statistically significant differences at level $p<0.05$

cant interactions between conditions and prior demographic statuses for the level of myside biases on all statements except for the Marijuana statement 2. Results are summarized in Table 2.

\section{Discussion}

As can be seen in the results, mindfulness induction failed to affect scores on FFMQ, 
short-term mindfulness induction and lecture on biases were insufficient to change the degree of miserly processing or the degree of myside bias (with one exception, which could be most likely attributed to violation of assumptions of two-way ANOVA). We can divide the possible reasons for this failure into several groups: problems with the method of inducing mindfulness, problems on the part of participants and/or lack of impact of short-term mindfulness. Using recordings for guided meditation might be problematic, recordings are usually merely accompanying books that give meditators more detailed background; lack of detailed instructions might have caused failure to induce mindfulness. If using translated recording, future researchers interested in the shortterm mindfulness induction paradigm should also pay attention to the choice of instructor, an inexperienced instructor might be actually detrimental to mindfulness induction. The use of a professional mindfulness meditation instructor is preferred (due to better control of voice, etc.), as demonstrated by Hafenbrack et al. (2013). But giving instructions before meditation might be even more preferable, since repeated instances of silence and voice instructions in the recording were deemed distracting by several participants. The environment could have also played a role, distracting noises and relative discomfort might have reduced the effect of induction. Secondly, motivation of participants could have been low or the sample could have been too small (although Hafenbrack et al., 2013 used similarly sized sample). There might have also been an effect of delayed testing due to transfer of students to a different classroom. There is also a possibility, that short-term mindfulness might not impact dependent variables, but this conclusion cannot be drawn from the currently reported results due to possible failure of mindfulness induction. This study should be understood as a preliminary study that can contribute to the methodology of further studies and help overcome potential pitfalls when trying to induce mindfulness. Long-term mindfulness training might have a larger effect on rationality, but short-term paradigm remains a viable and less time-consuming alternative as well. However, induction must be done attentively. The current study, among other things, shows that induction of mindfulness depends also on the quality of instructions given and this might reduce accessibility and practicality of shortterm mindfulness when applied in real life situations. Further studies might also incorporate an experimental design with pre-tests and post-tests, which I have not used due to a possible effect of pre-testing. Other studies rarely use control groups or pre-test posttest measurement of mindfulness in relation to interventions (or are not even measuring levels of mindfulness after intervention), as recent meta-analysis of studies on mindfulness-based interventions has shown (Visted, Vollestad, Nielsen, \& Nielsen, 2015). Thus, my study at least partially improves on the quality of research in this area. When compared to the study (Hafenbrack et al., 2013) on which this study is based, it can be concluded that short-term mindfulness intervention might affect only a handful of biases (e.g., sunk cost bias) or it might be a case that quality of intervention is of greatest importance. It might also be possible, that FFMQ for a short-term mindfulness intervention was unnecessarily long (effect of intervention can diminish or disappear in the meantime) and items could not be sufficiently related to their very recent experience, as the 
items are more focused on long-term and repeated experiences. Using a few items with the Likert scale as Hafenbrack et al. (2013) did might be a better solution. Lastly, of some interest is also the result, that a lecture on biases has not been effective in changing the degree of biases. This result should also be studied further.

Received November 15, 2015

\section{References}

Arch, J. J., \& Craske, M. G. (2006). Mechanisms of mindfulness: Emotion regulation following a focused breathing induction. Behaviour Research and Therapy, 44(12), 1849-1858. doi:10.1016/ j.brat.2005.12.007

Baer, R. A., Smith, G. T., Hopkins, J., Krietemeyer, J., \& Toney, L. (2006). Using self-report assessment methods to explore facets of mindfulness. Assessment, 13(1), 27-45. doi:10.1177/ 1073191105283504

Emanuel, A. S., Updegraff, J. A., Kalmbach, D. A., \& Ciesla, J. A. (2010). The role of mindfulness facets in affective forecasting. Personality and Individual Differences, 49(7), 815-818. doi: $10.1016 /$ j.paid.2010.06.012

Frederick, S. (2005). Cognitive reflection and decision making. Journal of Economic Perspectives, 19(4), 25-42. doi:10.1257/ 089533005775196732

Hafenbrack, A. C., Kinias, Z., \& Barsade, S. G. (2013). Debiasing the mind through meditation: Mindfulness and the sunk-cost bias. Psychological Science, (December 2013). doi:10.1177/ 0956797613503853

Heeren, A., Van Broeck, N., \& Philippot, P. (2009). The effects of mindfulness on executive processes and autobiographical memory specificity. Behaviour Research and Therapy, 47(5), 403409. doi:10.1016/j.brat.2009.01.017

Jankowski, T., \& Holas, P. (2014). Metacognitive model of mindfulness. Consciousness and Cognition, 28, 64-80. doi:10.1016/j.concog.2014. 06.005

Kabat-Zinn, J. (1994). Wherever you go, there you are: Mindfulness meditation in everyday life.
Hachette Books. Retrieved from https://books. google.sk/books?id=-g-OSXrZeYYC

Kabat-Zinn, J. (2005). Coming to our senses: Healing ourselves and the world through mindfulness. Hachette Books. Retrieved from https:// books.google.sk/books?id=RwkH XdH840C

Kiken, L. G., \& Shook, N. J. (2011). Looking up: Mindfulness increases positive judgments and reduces negativity bias. Social Psychological and Personality Science, 2(4), 425-431. doi:10.1177/ 1948550610396585

Moore, A., \& Malinowski, P. (2009). Meditation, mindfulness and cognitive flexibility. Consciousness and Cognition, 18(1), 176-186. doi:10.1016/ j.concog.2008.12.008

Mrazek, M. D., Franklin, M. S., Phillips, D. T., Baird, B., \& Schooler, J. W. (2013). Mindfulness training improves working memory capacity and GRE performance while reducing mind wandering. Psychological Science, 24(April), 776-781. doi:10.1177/0956797612459659

Noone, C., Bunting, B., \& Hogan, M. J. (2016). Does mindfulness enhance critical thinking? Evidence for the mediating effects of executive functioning in the relationship between mindfulness and critical thinking. Frontiers in Psychology, 6(January), 1-16. doi:10.3389/fpsyg.2015.02043

Stanovich, K. (2011). Rationality and the reflective mind. London: Oxford University Press.

Stanovich, K. E., \& West, R. F. (2007). Natural myside bias is independent of cognitive ability. Thinking \& Reasoning, 13(3), 225-247. doi: 10.1080/13546780600780796

Teper, R., \& Inzlicht, M. (2013). Meditation, mindfulness and executive control: The importance of emotional acceptance and brain-based performance monitoring. Social Cognitive and Affective Neuroscience, 8(1), 85-92. doi:10.1093/scan/ nss045

Toplak, M. E., West, R. F., \& Stanovich, K. E. (2014). Assessing miserly information processing: An expansion of the Cognitive Reflection Test. Thinking \& Reasoning, 20(2), 147-168. doi:10.1080/13546783.2013.844729

Visted, E., Vollestad, J., Nielsen, M. B., \& Nielsen, G. H. (2015). The impact of group-based mindfulness training on self-reported mindfulness: A systematic review and meta-analysis. Mindfulness, 6(3), 501-522. doi:10.1007/s12671-0140283-5 